\title{
DEPOSITION OF PETROLEUM HYDROCARBONS WITH SEDIMENT TRAPPED IN SNOW IN ROADSIDE AREAS
}

\author{
Larysa Mykhailova ${ }^{\mathrm{a}, \mathrm{b}}$, Thomas Fischer ${ }^{\mathrm{b}}$, Valentina Iurchenko ${ }^{\mathrm{a}}$ \\ ${ }^{a}$ Kharkiv National Automobile and Highway University, 25 Petrovskoho str., Kharkiv, Ukraine \\ ${ }^{b}$ Brandenburg University of Technology Cottbus-Senftenberg, Central Analytical Laboratory, \\ Konrad-Wachsmann-Allee 6, 03046 Cottbus, Germany
}

Submitted 14 Aug. 2013; accepted 28 Jan. 2014

\begin{abstract}
Total petroleum hydrocarbon (TPH) deposition rates were determined along various roads using the natural snow cover as deposition trap. Daily deposition rates decreased with distance from the roads, which coincided with long-term TPH accumulation in roadside soils. Scanning electron microscopy (SEM-EDX) of the snow meltwater sediment revealed occurrence of carbon-rich plaques, which were identified as hydrocarbons using FTIR-microscopy. GC-MS revealed that the compounds extracted from the sediment consisted of an unresolved complex hydrocarbon mixture (UCM). Individual n-alkanes could not be resolved in the sediment extract, whereas TPHs extracted from soils contained a series of $n$-alkanes peaking at C25-C27. The proportion of UCM compounds from TPHs decreased with distance from road. We conclude that high-boiling hydrocarbons bind to coarse mineral dust and/or to splash water and vehicle spray, which preferentially deposit within a $10 \mathrm{~m}$ roadside strip.
\end{abstract}

Keywords: vehicle spray, unresolved complex hydrocarbon mixture, $n$-alkanes, dust deposition, soil contamination.

\section{Introduction}

The main sources of traffic pollution in roadside soils are leakage and combustion of oil and fuel, wear from tires and from road furniture, de-icing agents as well as accidental spillages (DWW 2003). The widespread use of hydrocarbons in fuels causes their predominance among organic atmospheric pollutants, and petroleum products are the major source of anthropogenic hydrocarbon pollutants found in the atmosphere (Mykhailova et al. 2013; Adeniyi, Owoade 2010; Okonkwo et al. 2006; Manahan 1993). Total petroleum hydrocarbons (TPH) from fossil sources are not readily biodegradable as compared to biomass or soil organic matter, which have been demonstrated to be consumed during hydrocarbon degradation (Mykhailova et al. 2013; Zyakun et al. 2011; Dilly et al. 2011). However, $\mathrm{n}$-alkanes have been reported to degrade more rapidly in soil and water than components of the unresolved complex mixture (UCM) contained in mineral oils (Reddy et al. 2002). Once deposited on the surface, hydrocarbons may persist and bioaccumulate in environmental media (Alloway 1992), infiltrate into groundwater aquifers via leaching or into surface aquifers by runoff with severe effects on plants (Adam, Duncan 2002; Masakorala et al. 2013), humans and animals (Amadi et al. 1996; Albers 1995). Organic contaminants in roadside soils have been receiving considerable attention as a result of traffic intensity (Mykhailova et al. 2013; Adeniyi, Owoade 2010; Biasioli, Ajmone-Marsan 2007; Okonkwo et al. 2006; Unger, Prinz 1992).

Car emissions to the air, mainly incompletely burnt gases and dust particles, contribute to the background concentration in the atmosphere and are deposited over large distances from the road (Schipper et al. 2007). However, elevated amounts of petroleum hydrocarbons were reported from within a narrow strip ranging from 10-25 m (Unger, Prinz 1992; Iurchenko et al. 2013; Mykhailova et al. 2013) up to $50-100 \mathrm{~m}$, which were attributed to the influence of vehicle spray (Schipper et al. 2007).

It was the aim of this study to determine deposition rates of total petroleum hydrocarbons (TPH) on roadside soils in Kharkov, Ukraine, and to elucidate the role of near-road sediment deposition under no-runoff conditions in a situation of a considerable age of the vehicle fleet (UNECE Transport Division Database, 31.12.2008),

Corresponding author: Thomas Fischer

E-mail: thomas.fischer@tu-cottbus.de 
which typically is characterized by elevated oil leakage and tailpipe emissions.

The natural snow cover was used as deposition trap, which offers two main advantages: (1) Using meteorological snowfall data, the time period of deposition can be determined exactly; (2) Snow with its maximal temperature of $0{ }^{\circ} \mathrm{C}$ minimizes evaporative hydrocarbon losses from the surface. Long-term accumulation of TPH was further investigated in soils, and the sediment trapped in snow was investigated using scanning electron microscopy, equipped with X-ray detection (SEM-EDX) and Fourier transformed infrared (FTIR) microscopy.

\section{Material and methods}

\subsection{Sampling sites}

Soil samples were collected according to ISO 10381-2 (2003) at distances of 1, 6-8, 15, 40, 60 and $100 \mathrm{~m}$ in October 2010 from various asphalt roads in Kharkov, Ukraine (mean annual temperature: $7.5^{\circ} \mathrm{C}$, mean annual precipitation: $520 \mathrm{~mm}$ ). According to AG Boden (2005), the soils were characterized as chernozems developed on loess, the soil texture was sandy to clayey silt. The background organic $\mathrm{C}$ concentration of the soils ranged from 22 to $27 \mathrm{~g} \mathrm{~kg}^{-1}$, the content of carbonates was negligible (Mykhailova et al. 2013). Five replicates along a $100 \mathrm{~m}$ section at the windward (Akademika Pavlova and

a)

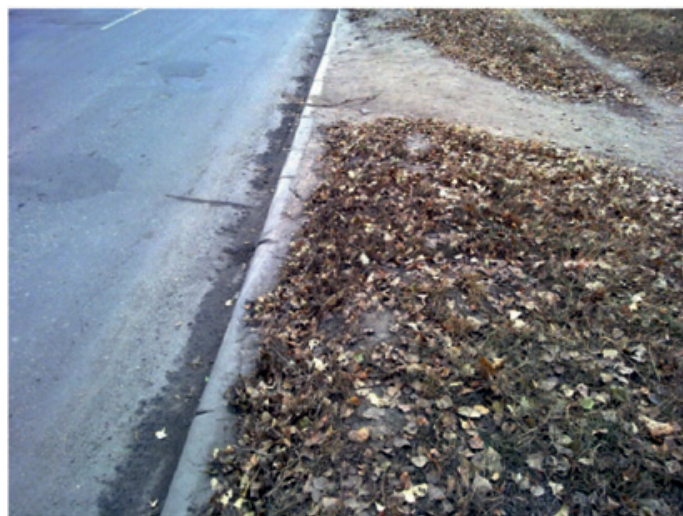

b)

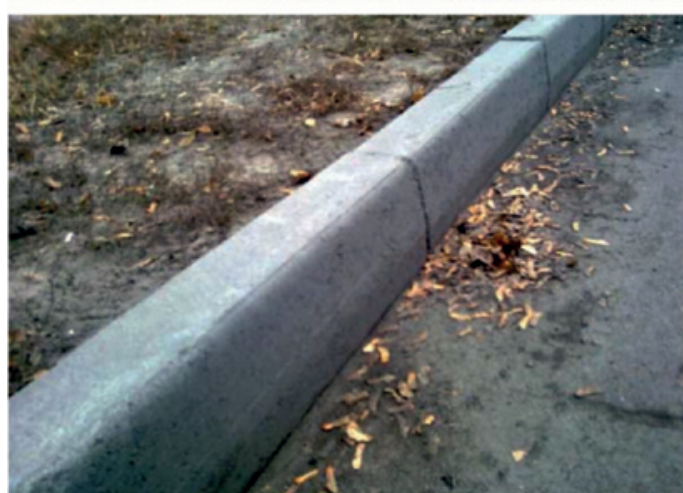

Fig. 1. Roadside of Akademika Pavlova street (a) and Traktorostroiteley avenue (b). Surface runoff can be excluded the given study, because all roads were confined by curbs
Traktorostroiteley av. only) and the leeward sides of the roads, as referred to the long-term wind direction, were sampled. The ground vegetation cover consisted of ruderal grass species. No road runoff could be observed, because all roads investigated were confined by curbs (Fig. 1). Instead, road traffic on ponding water caused appearance of splash water and vehicle spray during and after rain events, or after application of de-icing agents.

Snow samples, residing in the roadside area for a time period of 19 days, were collected from the windward and leeward sides at 5 points from areas of $20 \times 20 \mathrm{~cm}^{2}$ at distances of 2 and $8 \mathrm{~m}$ from the roads to the total depth of the snow cover following the general rules of volumebased sampling. To avoid hydrocarbon adsorption to the walls of the sampling containers as well as gaseous hydrocarbon losses, samples were sealed in glass containers immediately after collection and transported to the lab. Snow sediment was extracted from fresh meltwater after melting at $4{ }^{\circ} \mathrm{C}$ using $0.2 \mu \mathrm{m}$ membrane filters, and was air-dried at ambient room temperature.

\subsection{Analytical procedures}

TPH concentrations in soil and snow were determined gravimetrically according to DIN 38409-56 (2009) after triple extraction of $20 \mathrm{~g}$ soil or in the entire amount of fresh meltwater from the snow samples, respectively, with $50 \mathrm{~mL}$ hexane p.a., clean up over a short aluminium oxide column, and solvent evaporation to constant weight at $40^{\circ} \mathrm{C}$.

$\mathrm{TPH}$ and fractional composition of petroleum hydrocarbons of selected soil and snow meltwater samples were further determined using GC-MS (Carlo Erba, Fisons) after triple extraction of $2 \mathrm{~g}$ soil with $5 \mathrm{~mL}$ hexane for residue analysis, clean up over a short fluorosil column, and solvent evaporation under hydrocarbon-free nitrogen at $20{ }^{\circ} \mathrm{C}$ to a sample volume of $10-100 \mu \mathrm{L}$, depending on the results of the gravimetric hydrocarbon determination. The analytical procedure corresponded to EN ISO 9377-2 (2001). A SGE HT8 column at $2 \mathrm{~mL} \mathrm{~min}^{-1}$ linear Helium flow with $1 \mu \mathrm{L}$ split injection at a split ratio of 20:1 was used in GC-MS. Injection temperature was $300{ }^{\circ} \mathrm{C}$. The column temperature was $70^{\circ} \mathrm{C}$ during injection, was increased after 1 min with a heating rate of $30 \mathrm{~K} \mathrm{~min}^{-1}$ and held constant for $20 \mathrm{~min}$ after reaching $320^{\circ} \mathrm{C}$. For detection, positive electron impact ionization (EI+) at $70 \mathrm{eV}$ and MS full scan mode with $\mathrm{m} / \mathrm{z}$ ranging from 50 to 250 was used. Commercial diesel fuel and Hewlett Packard alkane standard Part. No. 18710-60170 were used for quantification and identification of total hydrocarbons and n-alkanes, respectively (Mykhailova et al. 2013).

Volatile organic compounds (VOC, boiling point $<250{ }^{\circ} \mathrm{C}$, alkane chainlength $<\mathrm{C} 15$ ), semi-volatile organic compounds (SVOC, boiling point $250-380{ }^{\circ} \mathrm{C}$, alkane chainlength $\mathrm{C} 15-\mathrm{C} 23$ ) and organic compounds associated with particulate matter (PM) or particulate organic matter 
(POM, boiling point $>380^{\circ} \mathrm{C}$, alkane chainlength $>\mathrm{C} 23$ ) were identified in the chromatograms using the total ionic current (TIC) after elimination of siloxane signals resulting from column bleeding. The proportion of UCM components in soil extracts was determined by subtraction of the peak area of resolved peaks from the total chromatogram peak area, related to the total chromatogram area.

Scanning electron microscopy (Zeiss DSM 962), equipped with energy dispersive X-ray fluorescence detection (EDXRF, Oxford Instruments), as well as FTIR microscopy (Thermo Centaur $\mu$ s) were used for microstructural analysis of the meltwater sediment. FTIR measurements were performed in diffuse reflectance mode with Kubelka-Munk correction and with a spectral resolution of $4 \mathrm{~cm}^{-1}$ against a gold mirror as background. In FTIR spectroscopy, net peak heights were determined to account for the intense $\mathrm{OH}$ vibration peaking at $3400 \mathrm{~cm}^{-1}$ and for baseline drift in the $\mathrm{C}=\mathrm{O}$ region. Soil carbon was determined by dry combustion using a CNS Analyser (Elementar, Germany).

\subsection{Statistics}

Statistical procedures included analysis of variance (ANOVA) and the post-hoc Tukey-test after Bartletts test for homogeneity of variance. The Wilcoxon signed rank test was used if homogeneity of variance was not met. The $\mathrm{R}$ software suite was used for all statistical calculations.

Mattsons Win1st FTIR software was used for processing the FTIR spectra. Box-whisker-plots were used to depict median values (bold lines) and variation (upper and lower quartiles in boxes, data ranges as whiskers, outliers as circles) of $\mathrm{CH} / \mathrm{C}=\mathrm{O}$ signal ratios and the proportion of the chromatogram area of UCM compounds on the total chromatogram area.

\section{Results}

\subsection{Soil}

Soil TPH concentrations are given Table 1. Maximal values were observed in $1 \mathrm{~m}$ distance from the roads and amounted up to $>3000 \mathrm{mg} \mathrm{kg}^{-1}$ at a sampling depth of
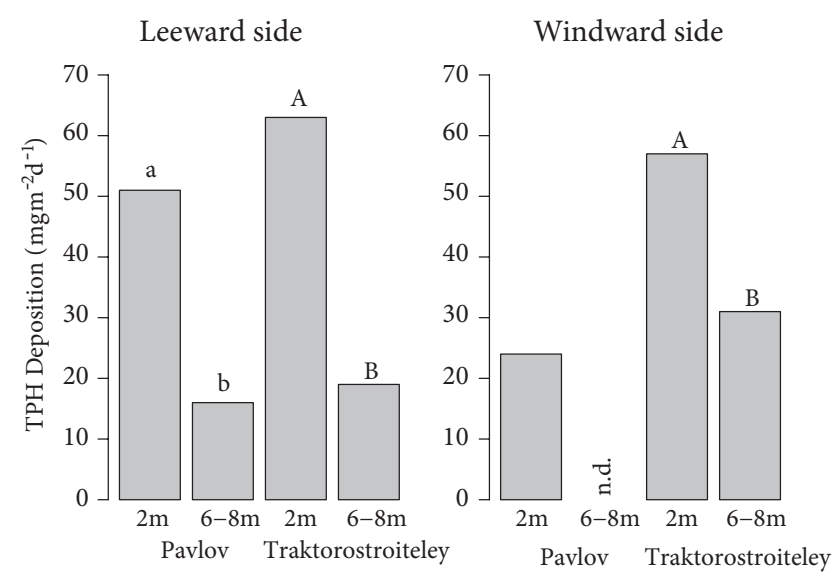

Fig. 2. Depositional flow of total petroleum hydrocarbons on snow. Same letters indicate non-significant ranges (Tukey-test, $p=0.05)$, n.d. - not determined.

$0-0.5 \mathrm{~cm}$. TPH concentrations decreased more or less exponentially with distance from road and with sampling depth (data not shown), where background values amounted to approximately $100 \mathrm{mg} \mathrm{kg}^{-1}$, which were reached in $100 \mathrm{~m}$ distance on the windward sides of the roads.

Clearly elevated above background values were observed on the leeward sides, reaching amounts of 390$540 \mathrm{mg} \mathrm{kg}^{-1}$ in $100 \mathrm{~m}$ distance from Pushkinskaya and Bluechera streets, respectively. Analysis of variance, where logarithmic distance and depth data were processed, revealed a significant influence of traffic intensity (F-Test, $p=$ 0.013 ), distance from road (F-test, $p<0.001$ ), sampling depth (F-test, $\mathrm{p}<0.001$ ), exposition to wind direction (Ftest, $p<0.001$ ) and period of road exploitation (F-test, $p<$ 0.001 ) on soil TPH concentrations.

\subsection{Meltwater sediment}

Depositional flow of total petroleum hydrocarbons to snow amounted up to $63 \mathrm{mg} \mathrm{m} \mathrm{m}^{-2} \mathrm{~d}^{-1}$ in $2 \mathrm{~m}$ distance, which was significantly (Tukey-test, $p=0.05$ ) higher than values obtained in $8 \mathrm{~m}$ distance regardless of the road investigated, and which amounted up to $31 \mathrm{mg} \mathrm{m}^{-2} \mathrm{~d}^{-1}$ (Fig. 2). Values tended to be higher on the leeward side,

Table 1. Soil total petroleum hydrocarbon (TPH) concentrations $\left(\mathrm{mg} \mathrm{kg}^{-1}\right)$, sampling depth $0-0.5 \mathrm{~cm}$, n.d. - not determined

\begin{tabular}{|c|c|c|c|c|c|c|c|c|c|}
\hline \multirow{2}{*}{ Road } & \multirow{2}{*}{$\begin{array}{c}\text { Period of } \\
\text { exploitation } \\
\text { (yrs.) }\end{array}$} & \multirow{2}{*}{$\begin{array}{c}\text { Traffic } \\
\text { Intensity } \\
\left(\text { veh. } \mathrm{h}^{-1}\right)\end{array}$} & \multirow{2}{*}{$\begin{array}{c}\text { Wind } \\
\text { exposition }\end{array}$} & \multicolumn{6}{|c|}{ Distance from road (m) } \\
\hline & & & & $1 \mathrm{~m}$ & $6-8 \mathrm{~m}$ & $15 \mathrm{~m}$ & $40 \mathrm{~m}$ & $60 \mathrm{~m}$ & $100 \mathrm{~m}$ \\
\hline \multirow{2}{*}{ Akademika Pavlova } & \multirow{2}{*}{40} & \multirow{2}{*}{2050} & Leeward & 3149 & n.d. & 347 & 233 & 225 & 125 \\
\hline & & & Windward & 785 & n.d. & 361 & 151 & 146 & 113 \\
\hline Pushkinskaya & 20 & 960 & Leeward & 1900 & n.d. & n.d. & n.d. & n.d. & 390 \\
\hline Bluechera & 40 & 1430 & Leeward & 2800 & n.d. & n.d. & n.d. & n.d. & 540 \\
\hline \multirow{2}{*}{ Traktorostroiteley } & \multirow{2}{*}{40} & \multirow{2}{*}{1120} & Leeward & 2766 & 2712 & 302 & 121 & 116 & 98 \\
\hline & & & Windward & 661 & 462 & 248 & 229 & 194 & 176 \\
\hline
\end{tabular}


a)

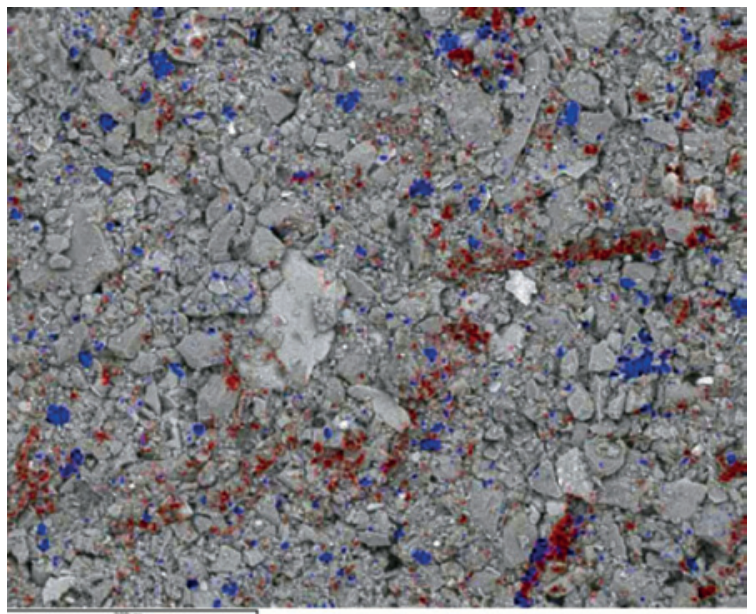

b)

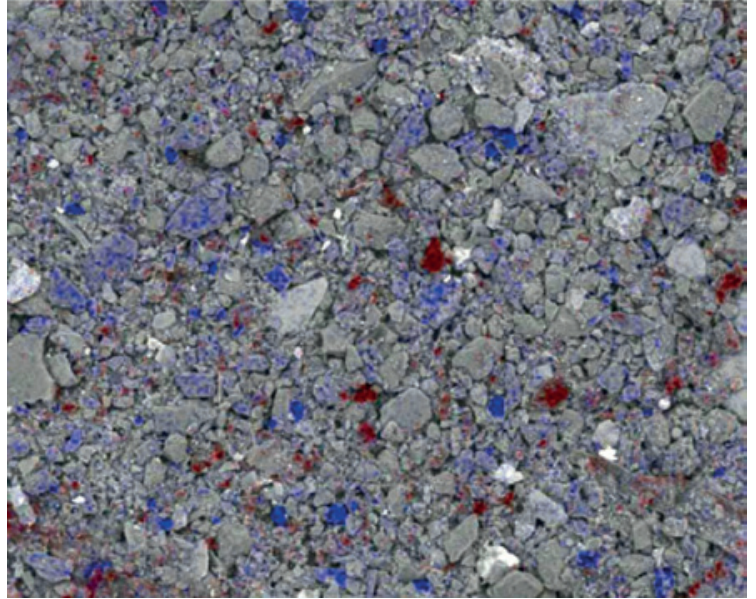

Fig. 3. SEM image of snow meltwater filter sediments: (a) sampling distance $1 \mathrm{~m}$; (b) sampling distance $20 \mathrm{~m}$. Carbon is mapped in red, Ca is mapped in blue colour. Ca may be geogenic (from loess) or anthropogenic (from de-icing agent) but did not differ significantly from the samples taken from the windward side.

The meltwater sediment mainly consisted of mineral fine sand and silt (mean particle diameter $<200 \mu \mathrm{m}, \mathrm{AG}$ Boden (2005)). SEM-EDX images of snow meltwater filter sediments, including $\mathrm{Ca}$ and $\mathrm{C}$ element maps, are depicted in Figure 3. Carbon-rich plaques on the surface of the sediment (mapped in red) were more pronounced in $1 \mathrm{~m}$ distance from the road compared to $8 \mathrm{~m}$.

A microscopic image of snow meltwater filter sediment sampled at $1 \mathrm{~m}$ distance from road is shown Figure 4, which exemplifies a dark-coloured measuring field

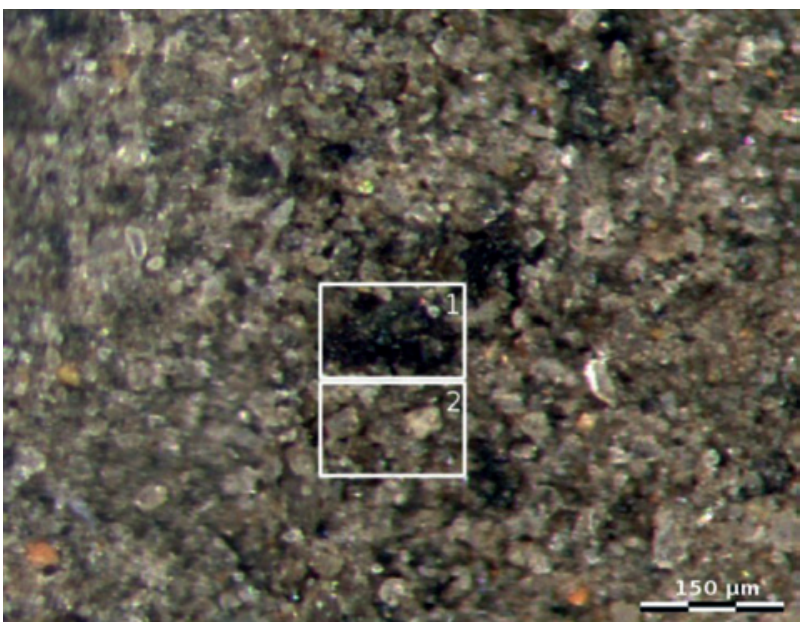

Fig. 4. Microscopic image of snow meltwater filter sediment sampled at $1 \mathrm{~m}$ distance from road: (1) dark-coloured measuring field; and (2) background measuring field for FTIR microscopy

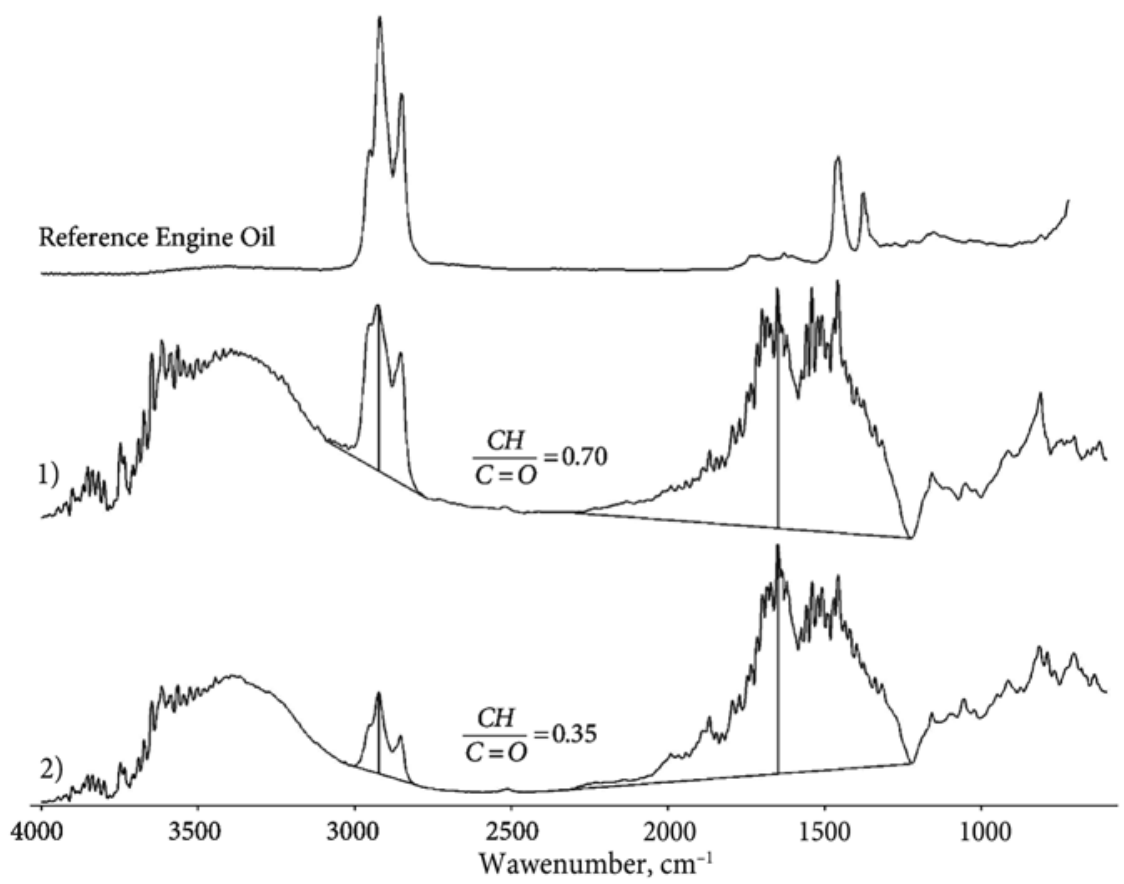

Fig. 5. FTIR spectra of: (1) the dark-coloured; and (2) the background measuring fields depicted in Figure 4. Engine oil is provided as analytical reference 
and its respective background for FTIR microscopy. The respective FTIR spectra are shown Figure 5.

FTIR spectra were generally characterized by a broad band peaking at $3400 \mathrm{~cm}^{-1}$, which can be attributed to the $\mathrm{OH}$ vibration originating from soil organic matter (alcoholic, phenolic $\mathrm{OH}$ ), from residual moisture $\left(\mathrm{H}_{2} \mathrm{O}\right)$, but also from $\mathrm{OH}$ bound to phyllosilicates. Individual peaks on the left shoulder of the broad OH-band (3500$4000 \mathrm{~cm}^{-1}$ ) most likely derive from phyllosilicatic inner surface Al-OH vibrations (mica, kaolinite, smectites). A sharp and intense band between 2800 and $3000 \mathrm{~cm}^{-1}$ characterizes the $\mathrm{CH}$ stretching vibration of saturated $\mathrm{C}$ structures, which is very typical for organic matter. Due to missing sharps peak between 3000 and $3100 \mathrm{~cm}^{-1}$ the presence of unsaturated aliphatic structures could not be confirmed. Peaks in the $1700-1750 \mathrm{~cm}^{-1}$ range typically characterize organic $\mathrm{C}=\mathrm{O}$ double bonds, like carboxyl-, carbonyl- and ester-C, which are typical for biogenic structures like biomass or soil organic matter, but absent in petroleum products (cf. reference Fig. 5).

The median values of the $\mathrm{CH} / \mathrm{C}=\mathrm{O}$ signal intensity ratios amounted to 0.57 and 0.36 for the dark coloured hot spots on snow meltwater filter sediment in 1 and $20 \mathrm{~m}$ distance from the roads, respectively, and significantly (paired Wilcoxon signed rank test, $p<0.01$ ) exceeded the respective neighbouring background values, which amounted to 0.34 and 0.15 for the reference measuring fields in 1 and $20 \mathrm{~m}$ distance from the roads, respectively (Fig. 6).

GC-MS revealed that hydrocarbons belonged mainly to the VOC and SVOC fraction in commercial diesel fuel, peaking at $\mathrm{C} 18$ (Fig. 7a), to the SVOC and PM/ POM fractions in soil extracts (Fig. 7b-d), but mainly to the fraction bound to particulate matter or POM in the meltwater filter extract. Typical series of $n$-alkane peaks could not be observed in the chromatograms of the meltwater filter extracts (Fig. 7e). Soil extracts had an n-alkane pattern resembling that of diesel fuel and consisting of a series of even- and odd-numbered chainlengths, but at a higher boiling range, peaking at $\mathrm{C} 25-\mathrm{C} 27$. On the other hand, filter extracts mainly contained an unresolved complex mixture (UCM) forming broad humps. The proportion of the chromatogram area of UCM components on the total chromatogram area for samples taken in $0-15 \mathrm{~m}$ distance from the roads significantly exceeded that of samples taken in 40-100 m distance (Wilcoxon rank sum test with continuity correction, $\mathrm{p}<0.001)$ and amounted to median values of $88 \%$ and $83 \%$, respectively (Fig. 7 f).

\section{Discussion}

The TPH concentration in soils depends on traffic intensity (Adeniyi, Owoade 2010; Biasioli, Ajmone-Marsan 2007; Okonkwo et al. 2006; Unger, Prinz 1992), as well as on meteorological and on further peripheral conditions,

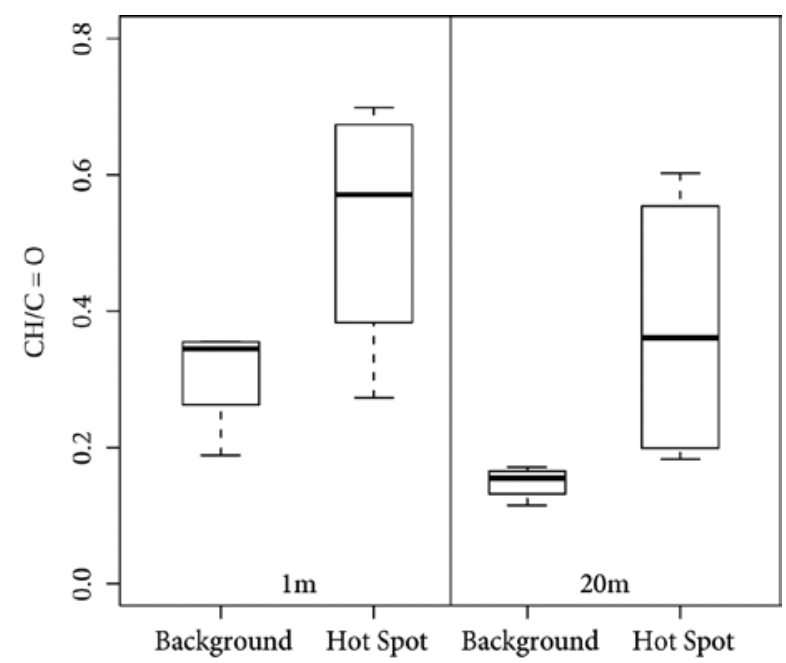

Fig. 6. Boxplot of the $\mathrm{CH} / \mathrm{C}=\mathrm{O}$ ratios for dark coloured hot spots and neighbouring background of snow meltwater filter sediment sampled at $1 \mathrm{~m}$ (left) and $20 \mathrm{~m}$ distance (right) from road. $n=5$

like wind, geomorphology, road construction, buildings, or on vegetation. Hence, TPH amounts along roadside soils reported in the literature vary widely, reaching maximum levels of approximately $1100 \mathrm{mg} \mathrm{kg}^{-1}$ soil in $1 \mathrm{~m}$ distance from a German freeway (50000 vehicles per day, Unger, Prinz 1992), and up to approximately $19500 \mathrm{mg} \mathrm{kg}^{-1}$ soil in Nigeria (Mykhailova et al. 2013; Adeniyi, Owoade 2010). The maximum levels found in this study amounted to $>3000 \mathrm{mg} \mathrm{kg}^{-1}$ soil at a traffic intensity of up to $25000 \mathrm{ve}-$ hicles per day. In particular, for perpendicular approaching wind, markedly higher atmospheric pollutant concentrations at the leeward side and slightly lower concentrations at the windward side were observed by Gromke and Ruck (2009), which may explore the higher soil TPH concentrations at the leeward side here. Unger, Prinz (1992) reported that background levels were reached at a distance of $10-25 \mathrm{~m}$ from the road, which could be confirmed by the findings of this study with elevated concentrations at $15 \mathrm{~m}$ distance from road (Table 1, Mykhailova et al. 2013).

SEM-EDX revealed carbon-rich plaques on the surface of the sediment, which were more pronounced in $1 \mathrm{~m}$ distance from the road compared to $8 \mathrm{~m}$. The XRF C signal (red) did not coincide with the Ca signal (blue), indicating the organic nature of the plaques instead of carbonates (Fig. 3). This observation confirms the findings of snow meltwater extraction that TPH deposition decreases with distance (Fig. 2). Stewart et al. (2013) suggested that available heavy hydrocarbon contaminants tended to sorb onto sediment as snow melts rather than partitioning into the aqueous phase. Consequently, hydrocarbons do not need to be adsorbed primarily to sediment, because dissolved or dispersed in splash water or vehicle spray hydrocarbons accumulate in the solid phase while water infiltrates into the soil (this process was simulated in our experiment by membrane filtration). 
FTIR microscopy (Fig. 4) revealed a wider $\mathrm{CH} / \mathrm{C}=\mathrm{O}$ ratio for the dark-spotted areas, indicating accumulation of compounds poor in carboxyl, carbonyl or ester bonds. Absence of narrow bands in the $3000-3100 \mathrm{~cm}^{-1}$ range further indicates the aliphatic nature of the respective compounds (Figs 5 and 6).

Diesel fuel typically contains large amounts of n-alkanes, which form a characteristic pattern in chromatograms (Fig. 7a) and which significantly exceed the signal intensity of an unresolved complex mixture (UCM). Contrarily, components of high-boiling oils or tar cannot be resolved sufficiently in one-dimensional GC and form a typical UCM hump (Wang et al. 2012). Thus, the appearance of diesel-like n-alkane patterns in roadside soil extracts points to incompletely combusted high-boiling components of fuel as the origin of soil hydrocarbons, which clearly can be distinguished in all soils regardless of the distance from the roads (Fig. 7b-e), and, hence, translocate over larger distances. It is unlikely that the series of n-alkanes found in soil extracts originates from biomass, because fatty acid biosynthesis commonly generates even-numbered alkyl chains by subsequently adding $\mathrm{C} 2$-units deriving from acetyl CoA. In contrast, mineral oil contains series of both even- and oddnumbered n-alkanes (Fig. 7a-d).

UCM predominantly found in near-road snow sediment also dominated in extracts of soils sampled within a $10 \mathrm{~m}$ range, whereas background soils contained smaller proportions of UCM compounds (Fig. 7f). It should be considered here that laboratory-produced meltwater samples typically suffer from heating during the melting a) 100

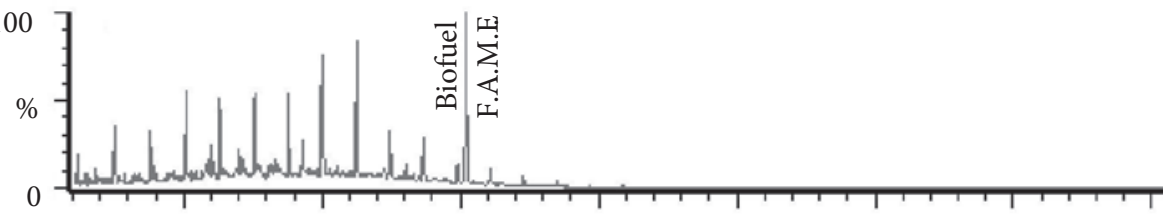

b) 100

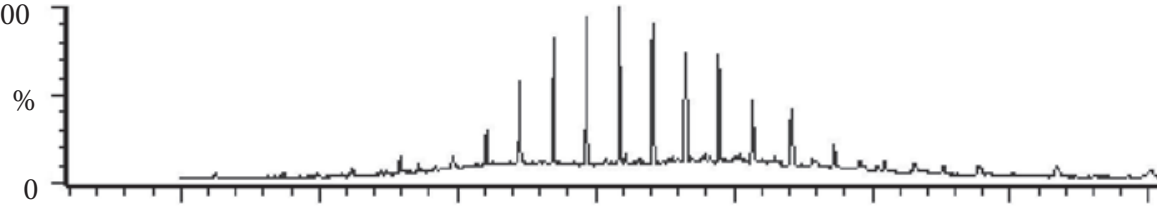

c) 100

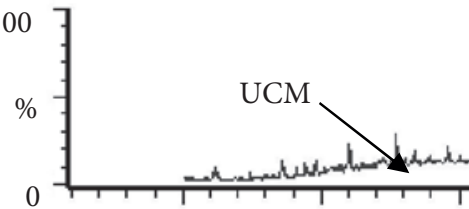

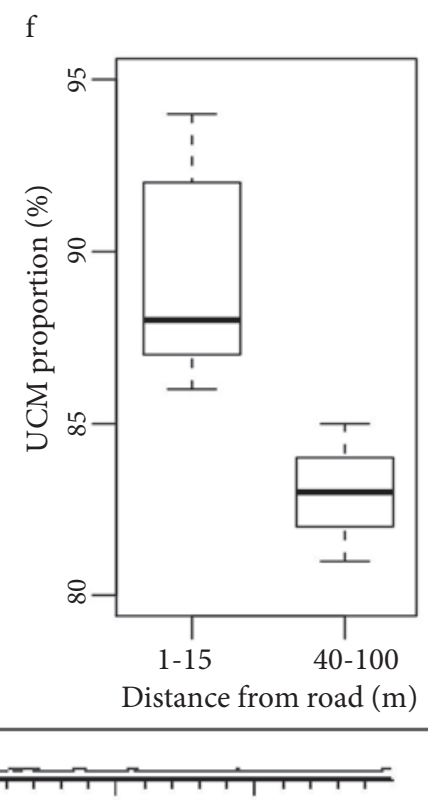

d) 100

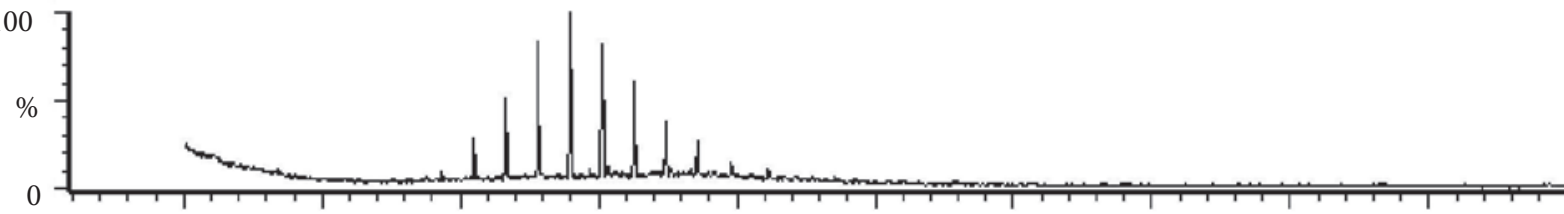

e) 100

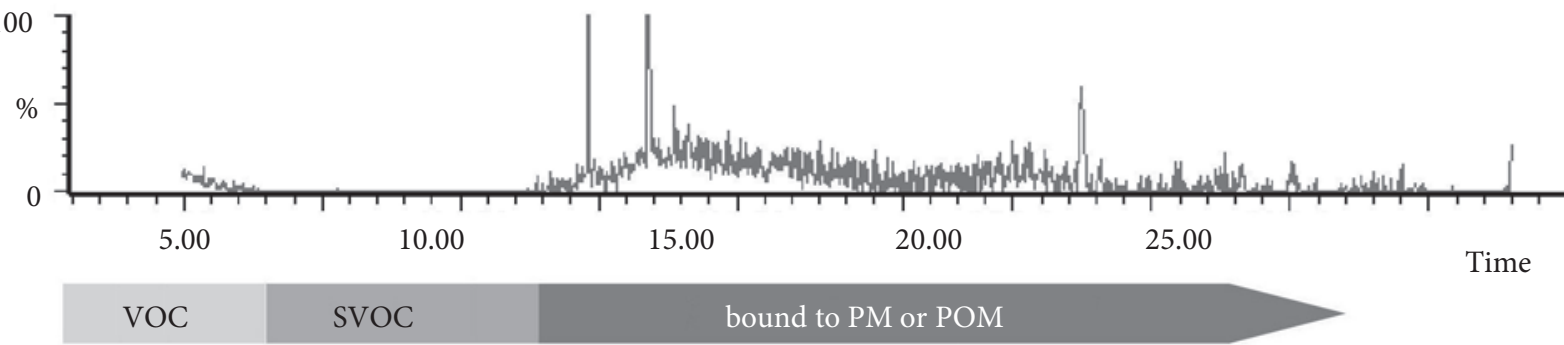

Fig. 7. GC-MS chromatograms of: (a) commercial diesel fuel, containing $5 \%$ fatty acid methyl esters (F.A.M.E.), purified hexane extract of roadside soils, distance; (b) $1 \mathrm{~m}$; (c) $40 \mathrm{~m}$; and (d) $100 \mathrm{~m}$ from Pushkinskaya street; (e) purified hexane filter extract; (f) boxplot of the percentage of unresolved complex mixture (UCM) compounds from total, distance classes 1-15 and 40-100 m, sampling depth $0-0.5 \mathrm{~cm}$ 
process; thus most volatile compounds likely volatilised prior or during this experiment (Stewart et al. 2013). However, our hypothesis of predominance of UCM meltwater sediment compared to soil is supported by the fact that roadside soils are subjected to higher temperatures: Soils would contain more light hydrocarbons if they would not heat up during summer, which is not possible for snow sediment prepared at a maximal temperature of $4{ }^{\circ} \mathrm{C}$.

High-boiling organic tailpipe emissions condense in the air forming secondary organic aerosol (SOA, "micro tarballs"). Gentner et al. (2012) reported that chainlengths in SOA formed from diesel car emissions range from C6 to $>\mathrm{C} 25$ and peak at around C20, whereas our results indicate a shifted range towards longer chains for soil extracts, peaking at $\mathrm{C} 25-\mathrm{C} 27$ (Fig. 7b-e). Car emissions to the air, mainly incompletely burnt gases and dust particles, are deposited over larger distances from the road (Schipper et al. 2007). Due to elevated TPH concentrations within a $10 \mathrm{~m}$ strip (Table 1), due to elevated hydrocarbon deposition rates close to the roads (Fig. 2), and due to the depositional patterns of vehicle spray reported by Schipper et al. (2007), we hypothesize that dry deposition of hydrocarbons bound to mineral soil particles, or wet deposition in conjunction with splashwater or vehicle spray would be the preferable pathways of hydrocarbon deposition on roadside soil. In contrast, direct adsorption of VOCs from the gas phase onto the soil surface and dry deposition of hydrocarbon carrying (fine) aerosol, including secondary organic aerosol (SOA) formed from tailpipe emissions, are considered to be less significant for elevated roadside TPH concentrations, because these fractions are known to be subjected to long-distance transport. While preferred sedimentation of these fractions within a couple of meters from their emission source cannot be expected, they well may contribute to elevated large-scale background levels. Further, typical VOCs (like low boiling alkanes, cycloalkanes, benzene, toluene, xylenes, napthalenes, etc. Gentner et al. 2012; Sheng et al. 2006) could not be extracted from any of the soils of this study. Due to their high vapour pressure typical VOCs likely prevail in the gas phase and adsorb little to the soil surface.

The decomposition of n-alkanes in soil is preferred compared to the decomposition of UCM hump forming iso-alkanes (Reddy et al. 2002). Hence, the presence of $\mathrm{n}$ alkane patterns in soil extracts after decades of road exploitation indicates the establishment of a dynamic equilibrium state, pointing to ongoing deposition of SVOC hydrocarbons into, as well as their ongoing decay in soils.

\section{Conclusions}

Summarizing the FTIR findings that snow sediment carries aliphatic substances poor in $\mathrm{C}=\mathrm{O}$, the GC-MS findings that predominantly UCM compounds could be extracted from this sediment, the spatial TPH depositional patterns on snow and soil, as well as the SEM finding that high-boiling petroleum hydrocarbons like engine oils or tar are associated with mineral particles belonging to the fine sand and silt fraction, it can be concluded that high boiling UCM hydrocarbons preferably deposit within a $10 \mathrm{~m}$ strip along roads. Under wet road conditions particles carrying hydrocarbons are likely bound to or washed out by splash water or vehicle spray, resulting in accumulation of UCM compounds near the road, whereas n-alkanes prevail at larger distances. A dynamic equilibrium between deposition, degradation and leaching of hydrocarbon fractions can be proposed. Further investigation of this equilibrium promises to utilize natural hydrocarbon degradation for the reclamation of contaminated sites. Elevated depositional hydrocarbon flow corresponded to long-term TPH accumulation in roadside soils.

\section{Acknowledgments}

We thank Wolfgang Wiehe (Brandenburg University of Technology Cottbus-Senftenberg, Central Analytical Laboratory) for technical assistance with SEM-EDX and Wolfgang Wieprecht (Brandenburg University of Technology Cottbus-Senftenberg, Chair of Atmospheric Chemistry and Air Pollution Prevention) for fruitful discussions. The authors are grateful to the Ministry of Education and Science of the Ukraine and to the German Academic Exchange Service (DAAD) for financial support.

\section{References}

Adam, G.; Duncan, H. 2002. Influence of diesel fuel on seed germination, Environmental Pollution 120(2): 363-370. http://dx.doi.org/10.1016/S0269-7491(02)00119-7

Adeniyi, A. A; Owoade, O. J. 2010. Total petroleum hydrocarbons and trace heavy metals roadside soils along the LagosBadagry expressway, Nigeria, Environmental Monitoring and Assessment 167(1-4): 625-630. http://dx.doi.org/10.1007/s10661-009-1078-3

Albers, P. H. 1995. Petroleum and individual polycyclic aromatic hydrocarbons, in Haffman, D. T.; Rattner, B. A.; Burton, G. A.; Cairns, J. (Eds.). Handbook of ecotoxicology. London: Lewis, 330-335.

AG Boden. 2005. Bodenkundliche Kartieranleitung, 5. Verbesserte und erweiterte Auflage. Schweizerbarthsche Verlagsbuchhandlung, Stuttgart, 142-147.

Alloway, B. J. 1992. Land contamination and reclamation, in Harrison, R. M. (Ed.). Understanding our environment. An introduction to environmental chemistry and pollution. Cambridge: Royal Society of Chemistry, 144-163.

Amadi, A.; Abbey, S. D.; Nma, A. 1996. Chronic effects of oil spill on soil properties and microflora of a rainforest ecosystem Nigeria, Water, Air, and Soil Pollution 86(1-4): 1-11. http://dx.doi.org/10.1007/BF00279142

Biasioli, M.; Ajmone-Marsan, F. 2007. Organic and inorganic diffuse contamination urban soils: the case of Torino (Italy), Journal of Environmental Monitoring 9(8): 862-868. http://dx.doi.org/10.1039/B705285E 
Dilly, O.; Nii-Annang, S.; Franke, G.; Fischer, T.; Buegger, F.; Zyakun, A. 2011. Resilience of microbial respiration, respiratory quotient and stable isotope characteristics to soil hydrocarbon addition, Soil Biology \& Biochemistry 43(9): 1809-1812. http://dx.doi.org/10.1016/j.soilbio.2010.09.026

DIN 38409-56. 2009. German standard methods for the examination of water, waste water and sludge - Parameters characterizing effects and substances (group H) - Part 56: Gravimetric determination of low volatile lipophilic substances after solvent extraction (H 56). $11 \mathrm{p}$.

DWW. 2003. The POLMIT Handbook, A practical guideline on causes and remedies of the pollution of groundwater and soil by road and traffic sources [online], [cited 05 August 2013]. Available from Internet: http://de.scribd.com/doc/78999080/ The-POLMIT-handbook-a-practical-guideline-on-causesand-remedies-of-the-pollution-of-groundwater-and-soil-byroad-and-traffic-sources

EN ISO 9377-2: 2001. Water quality - Determination of hydrocarbon oil index - Part 2: Method using solvent extraction and gas chromatography. $22 \mathrm{p}$.

Gentner, D. R.; Isaacman, G.; Worton, D. R.; Chan, A. W. H.; Dallmann, T. R.; Davis, L.; Liud, S.; Dayd, D. A.; Russel, L. M.; Wilson, K. R.; Weber, R.; Guha, A.; Harley, R. A.; Goldstein, A. H. 2012. Elucidating secondary organic aerosol from diesel and gasoline vehicles through detailed characterization of organic carbon emissions, PNAS 109(45): 1831818323. http://dx.doi.org/10.1073/iti4512109

Gromke, C.; Ruck, B. 2009. On the impact of trees on dispersion processes of traffic emissions street canyons, Boundary-Layer Meteorology 131(1): 19-34.

http://dx.doi.org/10.1007/s10546-008-9301-2

Iurchenko, V.; Mykhailova, L.; Fischer, T. 2013. Kinetic characteristics of petrochemicals transposition and accumulation soils of roadside area, in Transbaltica 2013 Conference Proceedings, 09-10 May, 2013, Vilnius, Lithuania. http://dx.doi.org/10.3846/transbaltica2013.016

ISO 10381-2: 2003. Soil quality - Sampling - Part 2: Guidance on sampling techniques. $23 \mathrm{p}$.

Manahan, E. S. 1993. Fundamentals of environmental chemistry. 4th ed. Chelsea: Lewis, 183-199.

Masakorala, K.; Yao, J.; Guo, H.; Chandankere, R.; Wang, J.; Cai, M.; Liu, H.; Choi, M. M. F. 2013. Phytotoxicity of longterm total petroleum hydrocarbon-contaminated soil - a comparative and combined approach, Water, Air \& Soil Pollution 224: 1553. http://dx.doi.org/10.1007/s11270-013-1553-x

Mykhailova, L.; Fischer, T.; Iurchenko, V. 2013. Distribution and fractional composition of petroleum hydrocarbons roadside soils, Applied and Environmental Soil Science 2013: 6 p. http://dx.doi.org/10.1155/2013/938703

Okonkwo, J. O.; Awofolu, O. R.; Moja, S. J.; Forbes, P. C. B.; Senwo, Z. N. 2006. Total petroleum hydrocarbons and trace metals street dusts from Tshwane metropolitan area, South Africa, Journal of Environmental Science and Health, Part A 41(12): 2789-2798. http://dx.doi.org/10.1080/10934520600966920

Reddy, C. M.; Eglinton, T. I.; Hounshell, A.; White, H. K.; Xu, L.; Gaines, R. B.; Frysinger, G. S. 2002. The West Falmouth oil spill after thirty years: the persistence of petroleum hydrocarbons marsh sediments, Environmental Science \& Technology 36(22): 4754-4760. http://dx.doi.org/10.1021/es020656n

Sheng, G. J.; Goldberg, J. M.; Harigaya, R.; Ty, J. C. 2006. GS-MS determination of volatile organic compounds gasoline and diesel emissions, Dartmouth Undergraduate Journal of Science Spring issue: $47-53$.

Schipper, P. N. M.; Comans, R. N. J.; Dijkstra, J. J.; Vergouwen, L. 2007. Runoff and windblown vehicle spray from road surfaces, risks and measures for soil and water, Water Science and Technology 55(3): 87-96. http://dx.doi.org/10.2166/wst.2007.076

Stewart, M.; Holden, A.; Haveroen, M.; Ulrich, A. 2013. Quantification of hydrocarbon contaminants meltwater and sediment a city snow pile, Journal of Environmental Engineering 139(2): 295-301. http://dx.doi.org/10.1061/(ASCE)EE.1943-7870.0000606

UNECE. 2008. United Nations Economic Commission for Europe Transport Division Database [online], [cited 08 August 2013]. Available from Internet: http://w3.unece.org/pxweb/ database/STAT/40-TRTRANS/02-TRRoadFleet/?lang=1

Unger, H.-J.; Prinz, D. 1992. Verkehrsbedingte Immissionen Baden-Württemberg - Schwermetalle und organische Fremdstoffe straßennahen Böden und Aufwuchs. Ministerium für Umwelt Baden-Württenberg, Luft, Boden, Abfall, Heft 19.

Wang, Z.; Yang, C.; Yang, Z.; Hollebone, B.; Brown, C. E.; Landriault, M.; Sun, S.; Mudge, S. M.; Kelly-Hoopere, F.; Dixon, D. G. 2012. Fingerprinting of petroleum hydrocarbons (PHC) and other biogenic organic compounds (BOC) oilcontaminated and background soil samples, Journal of Environmental Monitoring 14(9): 2367-2381. http://dx.doi.org/10.1039/C2EM30339F

Zyakun, A.; Nii-Annang, S.; Franke, G.; Fischer, T.; Buegger, F.; Dilly, O. 2011. Microbial activity and $13 \mathrm{C} / 12 \mathrm{C}$ ratio as evidence of N-Hexadecane and N-Hexadecanoic acid biodegradation agricultural and forest soils, Geomicrobiology Journal 28(7): 632-647.

http://dx.doi.org/10.1080/01490451.2010.489922

Larysa MYKHAILOVA is a PhD student of the Chair of Ecology of the Kharkiv National Automobile and Highway University.

Thomas FISCHER is a Doctor of Natural Sciences, Soil Scientist focussing on ecohydrology, microbial ecology, initial ecosystem development, as well as analytical and forensic chemistry. He is the Director of the Central Analytical Laboratory of the Brandenburg University of Technology Cottbus-Senftenberg.

Valentina IURCHENKO is a Doctor of Technical Sciences, Microbiologist, Hydro-Biologist and Ecologist, Professor of the Chair of Ecology of the Kharkiv National Automobile and Highway University, Head of the Chair of Life Safety \& Environmental Engineering of the Kharkiv National University of Construction and Architecture. 